\title{
Albendazole and mebendazole have low efficacy against Trichuris trichiura in school- age children in Kabale District, Uganda
}

Olsen, Annette; Namwanje, Harriet; Nejsum, Peter; Roepstorff, Allan Knud; Thamsborg, Stig Milan

Publication date:

2009

Document version

Publisher's PDF, also known as Version of record

Citation for published version (APA):

Olsen, A., Namwanje, H., Nejsum, P., Roepstorff, A. K., \& Thamsborg, S. M. (2009). Albendazole and mebendazole have low efficacy against Trichuris trichiura in school-age children in Kabale District, Uganda. Abstract from Joint Spring Symposium of the Danish Society for Parasitology \& Danish Society for Tropical Medicine \& International Health, Copenhagen, Denmark. 


\section{Er gedluendt teut sudt til biblo 203.2009}

Abstracts for the joint Spring Symposium 2009

Danish Society for Parasitology and

Danish Society for Tropical Medicine \& International Health

Format: 12-point, CG-Times, single spaced and fit in the box. It should contain title (bold), name of all authors (underline presenting author), affiliations, design, results and discussion.

Submission: Before February 23 to Martin Krarup Nielsen, University of Copenhagen, Faculty of Life Sciences, Dpt for Large Animal Sciences, Dyrlægevej 48, DK-1870 Frederiksberg C. mkn@life.ku.dk.

Subjects: Abstracts covering all aspects of parasitology and/or tropical medicine and international health are suitable for poster presentation. Abstracts falling within the topic of the Symposium or which are in other ways considered appropriate may be selected for oral presentation. Presenting authors will be notified about the form of their presentation no later than March 1, 2009.

Young Scientist Award: If you wish to have your presentation evaluated for the Young Scientist Awards you must provide the following information concerning age and academic degree.

Date, month and year of birth: 1

Month and year of latest degree:

(B.Sc., M.Sc., Ph.D. Please circle)

\section{ALBENDAZOLE AND MEBENDAZOLE HAVE LOW EFFICACY AGAINST TRICHURIS TRICHIURA IN SCHOOL-AGE CHILDREN IN KABALE DISTRICT, UGANDA}

Annette Olsen $^{\text {a }}$, Harriet Namwanje ${ }^{b}$, Peter Nejsum ${ }^{c}$, Allan Roepstorff ${ }^{c}$, Stig M. Thamsborg ${ }^{c}$ ${ }^{a}$ DBL-Centre for Health Research and Development, Department of Disease Biology, Faculty of Life Sciences, University of Copenhagen, Denmark. ${ }^{b}$ Vector Control Division, Ministry of Health, Kampala, Uganda. ${ }^{\mathrm{c}}$ Danish Centre for Experimental Parasitology, Department of Disease Biology, Faculty of Life Sciences, University of Copenhagen, Denmark

\section{Abstract}

Three groups of Trichuris trichiura-infected school-age children were treated with one dose 400 $\mathrm{mg}$ albendazole, $100 \mathrm{mg}$ mebendazole twice daily for $3 \mathrm{~d}$, or $100 \mathrm{mg}$ mebendazole twice daily for $5 \mathrm{~d}$. The albendazole study investigated cure and egg reduction rates and found that only 5 of 66 infected children were egg-negative $7 \mathrm{~d}$ post-treatment, giving a cure rate of $8 \%$ and a geometric mean egg reduction rate of $89 \%$. However, at day 14 post-treatment, all children were again egg-positive with significantly higher egg counts than at day $7(P<0.001)$. The two mebendazole studies aimed for the recovery of adult T. trichiura worms. After the $3 \mathrm{~d}$ course of mebendazole treatment, only four worms were recovered on days 3-5 after start of treatment from 2 of 34 infected children. With the $5 \mathrm{~d}$ course of mebendazole treatment, 10 of 21 infected children expelled a total of 27 worms. In the last case the first worm appeared on day 4 posttreatment, and the highest number of worms was recovered when the study ended at day 7 . In conclusion, even with the longest treatment regimen and collecting stool samples over seven consecutive days, only very few worms were recovered. The results of this study suggest that alternative drugs and/or alternative regimens in current control programmes against $T$. trichiura need renewed attention. 